'Atkinson, A. J., and Carroll, W. W., Fournal of the American Medical Association, 1964, 188, 183.

-Warren, K. W., Athanassiades, S., and Monge, J. I., American Fournal of Surgery, 1966, 111, 23.

- Grua, O. E., and McMurrin, J. A., American Fournal of Surgery, 1968, 116, 659.

10 Kasai, M., and Watanabe, I., Cancer, 1970, 25, 551.

\section{Pulmonary Alveolar Proteinosis}

In $1958 \mathrm{~S}$. H. Rosen and colleagues ${ }^{1}$ described what they considered to be a "remarkable disease of the lung that consists of the filling of the alveoli by a PAS-[periodic acid Schiff] positive proteinaceous material, rich in lipid." In these distal air spaces there is little if any cellular reaction. While this histological picture is the essential diagnostic feature of the disease, in clinical practice the condition is suggested by the radiographic appearances. To quote again from the original description: "There is a fine, diffuse, perihilar, radiating, feathery or vaguely nodular, soft density, resembling ... the pattern seen in severe pulmonary edema." These descriptions are still unchanged following reports now of over 150 cases in the world literature. The radiograph reflects irregular diffuse alveolar consolidation, which is the basis of the lung disturbance.

Clinically there may be few symptoms or signs to accompany a dramatic chest radiograph, but usually there is some shortness of breath, in part due to restriction of ventilation but mainly dependent on impaired gas transfer. Airways obstruction is not present. The patient may have some cough and produce scanty, usually mucoid, sputum. This may contain lipoproteinaceous material from the alveoli. ${ }^{2}$

It is a chronic disease and its natural history as shown in the records of 139 patients has been reviewed by J. M. Davidson and W. M. Macleod. ${ }^{3}$ The patients, more men than women, were aged from infancy to 72 years but were mostly between 30 and 50 . During varied periods of observation 48 of them recovered or greatly improved. Forty-five patients died, and in 38 of these cases death was directly due to the proteinosis or its complications. Infections were a common complication, especially fungalfor example, nocardiosis.

Looking for a causative factor Rosen and his colleagues could find no common occupational risk. Several patients were exposed to wood dusts, others to a wider variety of dusts and fumes, but many admitted no exceptional dust exposure. Experimentally a similar alveolar reaction has been found in rats exposed to siliceous dusts. ${ }^{45}$ In man similar features have been seen in silicosis, ${ }^{6}$ especially in the acute form, ${ }^{7}$ and even in tuberculosis, ${ }^{8}$ though here the affected alveoli are few and scattered. A further puzzle is the experimental response in rats to the same dusts, which on one occasion led to silicosis and on another produced lipoproteinosis. ${ }^{4}$ This suggests that an additional factor is required for its development. There is no evidence of an infective agent. The similarity of the alveolar reaction to that produced by the protozoon Pneumocystis carinii was noted by Rosen and his colleagues, but careful studies have excluded this as a possible infective agent. J. Gough 6 suggested that its production might depend in part on an altered state of immunity, and clinical support for this view is evident from the behaviour of the disease in children. A. R. Colon and colleagues, 9 studying the presentation in 23 infants, noted the frequent occurrence of lymphopenia, immunoglobulin deficiencies, and thymic alymphoplasia.

The source and nature of the intra-alveolar material is still in doubt. Rosen and his colleagues considered that much of it was formed by transformation of the septal cells, which, increasing in number, slough off and, disintegrating, fill the alveoli with the periodic-acid-Schiffpositive floccular, granular substance. More recent investigations show that some of these alveolar cells are phagocytic macrophages ingesting the lipid material, which in turn is derived from the type 11 or B granular pneumonocytes. These alveolar lining cells are considered to be the source of lung surfactant, and it appears that this substance accumulates in the alveoli either from overproduction ${ }^{10}$ or more likely as a result of inadequate clearing. ${ }^{11}$ Serum proteins have also been identified in the alveolar substance, suggesting that transudation of serum plays a part. ${ }^{4}$ Whether desquamative interstitial pneumonia, ${ }^{12}$ a condition in which the alveoli are filled with granular pneumonocytes and macrophages, is a related disorder remains to be determined.

While some patients recover spontaneously, it is still a disease with a high risk of progression, severe lung damage, and death. With so little known of its development, prevention is impossible to direct and treatment remains empirical. It would seem that antibiotics should be prescribed only when directly indicated. Corticosteroids should remain a last resort. There is an encouraging response in a worsening situation to pulmonary lavage. ${ }^{13}$

Pulmonary alveolar proteinosis is a newly recognized lung reaction rather than a new lung disease. Before the availability of modern histochemical techniques the reaction, so resembling pulmonary oedema, could easily have been overlooked. The search is now not for a new cause of death but for a finer understanding of the behaviour of the alveolus by work in the laboratory and by alert observation in clinical practice.

1 Rosen, S. H., Castleman, B., and Liebow, A. A., New England fournal of Medicine, 1958, 258, 1123.

Carlson, D. J., and Mason, E. W., American fournal of Clinical Pathology,

$1960,33,48$.
3 Davidson, J. M., and Macleod, W. M., British fournal of Diseases of the Chest, 1969, 63, 13.

4 Heppleston, A. G., Wright, N. A., and Stewart, J. A., Fournal of Pathology, $1970,101,293$.

5 Corrin, B., and King, E., Thorax, 1970, 25, 230.

Gough, J., British Medical fournal, 1967, 1, 629.

7 Gough, J., British Medical fournal, 1967, 1, 629.

8 Buechner, H. A., and Ansari, A., Diseases of the

8 Steer, A., Archives of Pathology, 1969, 87, 347.
- Colon, A. R., Lawrence, R. D., Mills, S. D., and O'Connell, E. J. American fournal of Diseases of Children, 1971, 121, 481.

10 Larson, R. K., and Gordinier, R., Annals of Internal Medicine, 1965, 62, 292.

11 Ramirez-R., J., and Harlan, W. R., American Fournal of Medicine, 1968, 45, 502 .

12 Liebow, A. A., Steer, A., and Billingsley, J. G., American fournal of Medicine, 1965, 39, 369 .

13 Ramirez-R., J., American Review of Respiratory Diseases, 1971, 103, 666.

\section{Congenital Pulmonary Lymphangiectasis}

Cystic disease of the lungs due to dilatation of the lymphatic vessels is one of the lesser known forms. The condition, known usually as congenital pulmonary lymphangiectasis, is characterized by intercommunicating thin-walled, endo- 
thelium-lined, fluid-filled cysts of greatly varying diameter situated in abundant subpleural, peribronchial, and interlobular connective tissue. The first case was described by Virchow $^{1}$ in 1856, and only three more cases were reported in the following 100 years. But after the publication of those three cases by $\mathrm{K}$. M. Laurence in $1955^{2}$ the number on record has now risen to over 50 , mostly in single case reports, though there have been two reviews and reports of larger series by Laurence $^{3}$ in 1959 and recently by N. E. France and R. J. K. Brown, ${ }^{4}$ each describing 11 new examples.

Typically, the patients develop respiratory distress with cyanosis very soon after birth, and it is not usually relieved by high concentrations of oxygen. ${ }^{4}$ They do not generally survive more than a few hours or days, though in a few reported cases in which the onset was later the subsequent course of the disease, though fatal, was much more protracted. One child, ${ }^{5}$ on whom the diagnosis was made on lung biopsy at 7 weeks, was still alive five years later ${ }^{6}$ but suffering from attacks of respiratory distress and wheezing precipitated by respiratory infections. The postmortem findings of the typical solid, bulky, poorly expanded lungs with lobular patterning and prominent subpleural lymphatic channels is as a rule unexpected, and the correct diagnosis is not generally arrived at until the histological sections are available. The pathologist has to differentiate congenital lymphangiectasis from dilated but normal lymphatics seen in hyaline membrane disease and hydrops fetalis; from cystic disease of bronchial origin, when there is usually some evidence of bronchial-type mucosa lining the spaces; and from interstitial emphysema, when a false lining to the emphysematous spaces is derived from the cells in the loose connective tissue of the interlobular septa and peribronchial tissue. ${ }^{2}$ The very rare pulmonary lymphangioma has distinctive appearances and should not present a diagnostic problem. In only two cases $^{5} 6$ has the diagnosis been made in life, even though in at least a quarter of the reported cases radiographs were available with their characteristic diffuse reticulation and a mottling or ground-glass appearance of the lung fields interspersed with small cystic areas. 48

The pathogenesis of congenital lymphangiectasis is unknown, but the most widely held theory is that of Laurence, who regards it as a developmental error. Normally at the fourteenth week of intrauterine life large lymphatic vessels and abundant connective tissue divide the lung parenchvma into distinct lobules. But by the twentieth week this lobulation has become less distinctive, with a reduction of both the lymphatic vessels and the connective tissue. Laurence postulated that in lymphangiectasis there is a failure of this normal regression of the lymphatic vessels and connective tissue, and that these elements continue to grow and maintain their early fetal proportions. Postmortem injection experiments ${ }^{6}$ and reconstruction of serial sections ${ }^{3}$ showed that the spaces are part of an intercommunicating network of abnormal vessels. These vary grossly in diameter along their length and do not represent isolated lymphatic spaces which have failed to link up, as suggested by J. T. Giammalvo.9

In half the reported cases pulmonary lymphangiectasis was apparently an isolated anomaly. In the others it was one of several anomalies, among them cardiovascular malformations. Though the particular heart malformation varied considerably, total anomalous pulmonary venous drainage was recorded in 12 cases, ${ }^{4} 610$ while four more had varieties of the hypoplastic left heart syndrome. In both these conditions the baby is likely to have had obstruction to the pulmonary venous flow in utero, which could result in increased lymphatic drainage, with the consequent retention of the large lymphatics of the early fetus. ${ }^{4} 6$ It is of interest that $J$. R. Esterly and E. O. Oppenheimer ${ }^{11}$ reponted lymphangiectasis and lymphatic proliferation in many of their cases of asplenia syndrome, for these patients are known to have various anomalies of the pulmonary veins or to suffer from pulmonary thromboembolism, and they are therefore likely to have an increased pulmonary lymphatic flow. It is of interest that agenesis of the spleen was recorded in four of the reported cases of congenital pulmonary lymphangiectasis. However, France and Brown cite 14 cases of total anomalous pulmonary venous drainage without lymphangiectasis that came to necropsy at ages ranging from 15 min to 11 months, whose variety of venous anomaly did not differ in any significant way from those who did have lymphangiectasis.

Congenital pulmonary lymphangiectasis, whether it is an isolated lesion or associated with cardiac and other anomalies, is almost certainly much commoner than the relatively few reported cases would suggest. Pooling the three reports of cases found in consecutive series of necropsies on stillbirths and newborn babies ${ }^{2} 12$ suggests that one case of pulmonary lymphangiectasis could be expected in every 170 postmortem examinations. Thus a greater awareness of the condition should lead to its more frequent diagnosis in the postmortem room and perhaps also in life. But unfortunately it seems doubtful whether anything much can be done for this condition, at least in its severer form.

\footnotetext{
1 Virchow, R. L. K., Gesammelte Abhandlungen zur Wissenschaftlichen Medizin, p. 982. Frankfurt, Meidinger, 1856.

2 Laurence, K. M., Fournal of Pathology and Bacteriology, 1955, 70, 325.

3 Laurence, K. M., Fournal of Clinical Pathology, 1959, 12, 62.

4 France, N. E., and Brown, R. J. K., Archives of Disease in Childhood, $1971,46,528$.

5 Javett, S. N., Webster, I., and Braudo, J. L., Pediatrics, 1963, 31, 416.

Noonan, J. A., Walters, L. R., and Reeves, J. T., American fournal of Diseases of Children, 1970, 120, 314.

7 Carter, R. W., and Vaughn, H. M., American Fournal of Roentgenology, Radium Therapy, and Nuclear Medicine, 1961, 86, 576.

8 Giedion, A., Muller, W. A., and Molz, G., Helvetica Paediatrica Acta, $1967,22,170$.

- Giammalvo, J. T., Laboratory Investigation, 1955, 4, 450.

10 Tan-Vinh, L., Cochard, A. M., and Trieu Dong, V., Archives Françaises de Pédiatrie, 1964, 21, 165.

11 Esterly, J. R., and Oppenheimer, E. H., Archives of Pathology, 1970, 90, 553.

12 Gleissner, P., Asante, F., and Schubert, G. E., Deutsche Medizinische Wochenschrift, 1969, 94, 1987.
}

\section{Second Opinion, Please}

Traditionally, dialogue between doctors at the patient's bedside has always been regarded as the essence of good consultation. But in recent years pressures on general practitioners and consultants alike have made it increasingly difficult for them to meet, and today any discussion is often carried out by letter or on the telephone. Nevertheless, such discussion still plays a valuable part in continuing postgraduate education, and in this week's B.M.F. we start a new series of articles, "Second Opinion, Please." These will record correspondence or dialogue over a point of diagnostic interest between general practitioners and consultants. The article by Dr. Andrew Smith and Dr. Hugh Jackson at p. 428 discusses a frequent problem in general practicewhen and how to investigate urinary infection in a childand future contributions will include articles devoted to subjects such as breast cancer and ankylosing spondylitis. 